\title{
Adjuvant corticosteroid therapy for critically ill patients with COVID-19
}

\author{
Xiaofan $\mathrm{Lu}^{1 \dagger}$, Taige Chen ${ }^{2 \dagger}$, Yang Wang ${ }^{3 \dagger}$, Jun Wang ${ }^{4 \dagger}$ and Fangrong Yan ${ }^{1 *}$
}

Dear Editor,

A substantial portion of patients with coronavirus disease (COVID-19) developed rapidly progressive pneumonia leading to acute respiratory distress syndrome (ARDS) and multiple organ dysfunctions, conditions associated with high mortality [1]. Adjuvant corticosteroid therapy of such patients is common in clinical practice, but evidence is scarce regarding the efficacy of adjuvant corticosteroids in patients who are critically ill with COVID-19.

We retrospectively reviewed medical records of adult patients with COVID-19 who were admitted to Tongji Hospital (Wuhan, China) from January 25 to February 25, 2020. Two hundred forty-four eligible patients who had complete records and were critically ill and treated with antiviral agents were enrolled. Critically ill patients were defined as those with ARDS $\left(\mathrm{PaO}_{2} / \mathrm{FiO}_{2} \leq 300\right.$ mmHg; when $\mathrm{PaO}_{2}$ is not available, $\mathrm{SpO}_{2} / \mathrm{FiO}_{2} \leq 315$ suggests ARDS) or sepsis with acute organ dysfunction [2]. We converted all preparations to hydrocortisoneequivalent doses (methylprednisolone 1:5, dexamethasone 1:25) [3]. The clinical outcome was 28 -day mortality after admission.

We adjusted for differences in baseline characteristics by propensity score, using multivariate logistic regression without regard to outcomes [4]. Potential confounders considered in propensity score matching (PSM) were variables included in the final model by step-wise backward elimination with $P<0.20$ [5]. Corticosteroid treatment effect on outcome was analyzed by multivariate logistic regression with

\footnotetext{
* Correspondence: f.r.yan@163.com

${ }^{+}$Xiaofan Lu, Taige Chen, Yang Wang and Jun Wang contributed equally to this work.

${ }^{1}$ State Key Laboratory of Natural Medicines, Research Center of Biostatistics and Computational Pharmacy, China Pharmaceutical University, Nanjing 210009, China

Full list of author information is available at the end of the article
}

adjustment for major variables (age, $\mathrm{SpO}_{2} / \mathrm{FiO}_{2}$, and lymphocytes) associated with mortality; individual propensity score was incorporated as a covariable to calculate the propensity-adjusted odds ratio (OR) [5]. PSM generated propensity score-matched pairs without replacement, and survival probability was compared by the Kaplan-Meier curve and analyzed with the log-rank test. Cox regression was used to estimate hazard ratio (HR) with $95 \%$ CI. For unadjusted comparisons, a two-sided $P<0.05$ was considered statistically significant.

Of the 244 critically ill patients with COVID-19, the median age was $62(50-71)$ years, and $52 \%$ were male. All patients were given antiviral therapy (e.g., oseltamivir, arbidol, lopinavir/ritonavir, ganciclovir, interferon- $\alpha$ ), and 151 (62\%) were given adjuvant corticosteroid treatment (median hydrocortisoneequivalent dosage 200 [range 100-800] mg/day). Five (5.4\%) and 79 (52.3\%) patients died in non-steroid and steroid groups, respectively. The median (IQR) administration duration of corticosteroid treatment was 8 (4-12) days. Multiple organ dysfunctions were more common in the steroid group than in the nonsteroid group. Multivariate analysis that adjusted for major mortality-associated variables and propensity score indicated that corticosteroid treatment was independent from overall mortality (adjusted OR 1.05; 95\% CI 0.15-7.46). One hundred forty-seven (60\%) had dyspnea and 87 (36\%) had ARDS, and subgroup analyses revealed corticosteroid treatment was not associated with 28-day mortality (both, $P>0.3$ ). Sixty-two patients in 31 pairs were matched (Table 1), and 28 -day mortality rate was $39 \%$ in case subjects and $16 \%$ in control subjects $(P=0.09)$. Likewise, addition of adjuvant corticosteroid therapy to standard antiviral treatment was not associated with 28-day mortality $(P=0.17$; Fig. 1$)$. However, 
Table 1 Baseline characteristics for steroid treatment and non-steroid treatment groups comprising critically ill patients with COVID19 before and after propensity score matching

\begin{tabular}{|c|c|c|c|c|c|c|}
\hline & \multicolumn{3}{|l|}{ Cohort study } & \multicolumn{3}{|c|}{ Case-control study (PSM) } \\
\hline & Steroid (151) & Non-steroid (93) & $P$ & Steroid (31) & Non-steroid (31) & $P$ \\
\hline Age, years & $64(53-71)$ & $59(47-69)$ & .09 & $57(51-69)$ & $58(50-67)$ & .98 \\
\hline Gender, male & $83(55)$ & $45(48)$ & .39 & $16(52)$ & $16(52)$ & 1 \\
\hline \multicolumn{7}{|l|}{ Signs and symptoms } \\
\hline Fever & $136(90)$ & $81(87)$ & .61 & $30(97)$ & $26(84)$ & .2 \\
\hline Dry cough & $112(74)$ & $57(61)$ & .05 & $21(68)$ & $21(68)$ & 1 \\
\hline Dyspnea & $94(62)$ & $53(57)$ & .5 & $20(65)$ & $19(61)$ & 1 \\
\hline Fatigue & $70(46)$ & $48(52)$ & .51 & $12(39)$ & $13(42)$ & 1 \\
\hline Expectoration & $69(46)$ & $30(32)$ & .05 & $12(39)$ & $12(39)$ & 1 \\
\hline Diarrhea & $45(30)$ & $22(24)$ & .37 & $10(32)$ & $7(23)$ & .57 \\
\hline Anorexia & $42(28)$ & $25(27)$ & .99 & $5(16)$ & $8(26)$ & .53 \\
\hline \multicolumn{7}{|l|}{ Original comorbidities } \\
\hline Hypertension & $61(40)$ & $34(37)$ & .64 & $16(52)$ & $12(39)$ & .44 \\
\hline Diabetes & $34(23)$ & $10(11)$ & .03 & $4(13)$ & $7(23)$ & .51 \\
\hline CVD & $15(10)$ & $13(14)$ & .45 & $2(7)$ & $2(7)$ & 1 \\
\hline COPD & $9(6)$ & $3(3)$ & .51 & 0 & $1(3)$ & 1 \\
\hline \multicolumn{7}{|l|}{ Vital signs } \\
\hline $\mathrm{T},{ }^{\circ} \mathrm{C}$ & 37.0 (36.2-38) & 36.7 (36.4-37.3) & .02 & $37(36.5-37.6)$ & $37(36.5-37.3)$ & .93 \\
\hline Breathing, rpm & $22(20-25)$ & $20(20-22)$ & $<.01$ & $21(20-24)$ & $20(20-22)$ & .08 \\
\hline Pulse, bpm & $92(82-105)$ & 88 (78-98) & .03 & 95 (78-106) & $93(82-100)$ & .51 \\
\hline $\mathrm{SpO}_{2} / \mathrm{FiO}_{2}$ & $259(121-303)$ & 297 (279-388) & $<.01$ & $291(212-452)$ & $294(246-396)$ & .57 \\
\hline \multicolumn{7}{|c|}{ Laboratory findings (WBCs, lymphocytes, neutrophils, platelets, $\times 10^{9} / \mathrm{L}$ ) } \\
\hline WBCs & $6.7(4.9-8.9)$ & $5.0(4.0-6.5)$ & $<.01$ & $6.6(4.0-8.6)$ & $5.1(3.5-6.8)$ & .12 \\
\hline Lymphocytes & $0.7(0.5-1.0)$ & $1.2(0.9-1.6)$ & $<.01$ & $0.9(0.5-1.3)$ & $1.1(0.6-1.2)$ & .64 \\
\hline Neutrophils & $5.4(3.6-7.6)$ & $3.2(2.4-4.2)$ & $<.01$ & $5.2(2.6-7.4)$ & $3.5(2.3-4.7)$ & .09 \\
\hline Platelets & $181(138-248)$ & $224(170-298)$ & $<.01$ & $168(138-214)$ & 206 (155-230) & .23 \\
\hline $\mathrm{HGB}, \mathrm{g} / \mathrm{L}$ & $130(117-141)$ & $127(117-139)$ & .42 & $128(118-138)$ & 125 (117-133) & .56 \\
\hline \multicolumn{7}{|l|}{ Organ function damage } \\
\hline ARDS & $81(54)$ & $6(7)$ & $<.01$ & $12(39)$ & $6(19)$ & .16 \\
\hline Septic shock & $69(46)$ & $2(2)$ & $<.01$ & $8(26)$ & $2(7)$ & .08 \\
\hline Myocardial infarction & $64(42)$ & $3(3)$ & $<.01$ & $10(32)$ & $3(10)$ & .06 \\
\hline AKI & $46(31)$ & $5(5)$ & $<.01$ & $8(26)$ & $3(10)$ & .18 \\
\hline DIC & $39(26)$ & $2(2)$ & $<.01$ & $6(19)$ & $2(7)$ & .26 \\
\hline Liver injury & $28(19)$ & $6(7)$ & $<.01$ & $7(23)$ & $3(10)$ & .3 \\
\hline \multicolumn{7}{|l|}{ Treatment } \\
\hline Anti-bacteria & $142(94)$ & $42(45)$ & $<.01$ & $25(81)$ & $26(84)$ & 1 \\
\hline Gamma globulin & $84(56)$ & $8(9)$ & $<.01$ & $11(36)$ & $8(26)$ & .58 \\
\hline MV & $78(52)$ & $4(4)$ & $<.01$ & $11(36)$ & $4(13)$ & .08 \\
\hline Muscle relaxant & $25(17)$ & 0 & $<.01$ & $4(13)$ & 0 & .12 \\
\hline HFNC & $21(14)$ & $1(1)$ & $<.01$ & $6(19)$ & $1(3)$ & .11 \\
\hline
\end{tabular}

Abbreviations: CVD cardiovascular disease, COPD chronic obstructive pulmonary disease, WBCs white blood cells, ARDS acute respiratory distress syndrome, $A K I$ acute kidney injury, DIC disseminated intravascular coagulation, $M V$ mechanical ventilation, HFNC high flow nasal cannula Continuous variables were described as the median (IQR) while categorical variables were expressed as frequencies (\%). Hypothesis testing using Fisher's exact test for categorical data and Mann-Whitney test for continuous data 


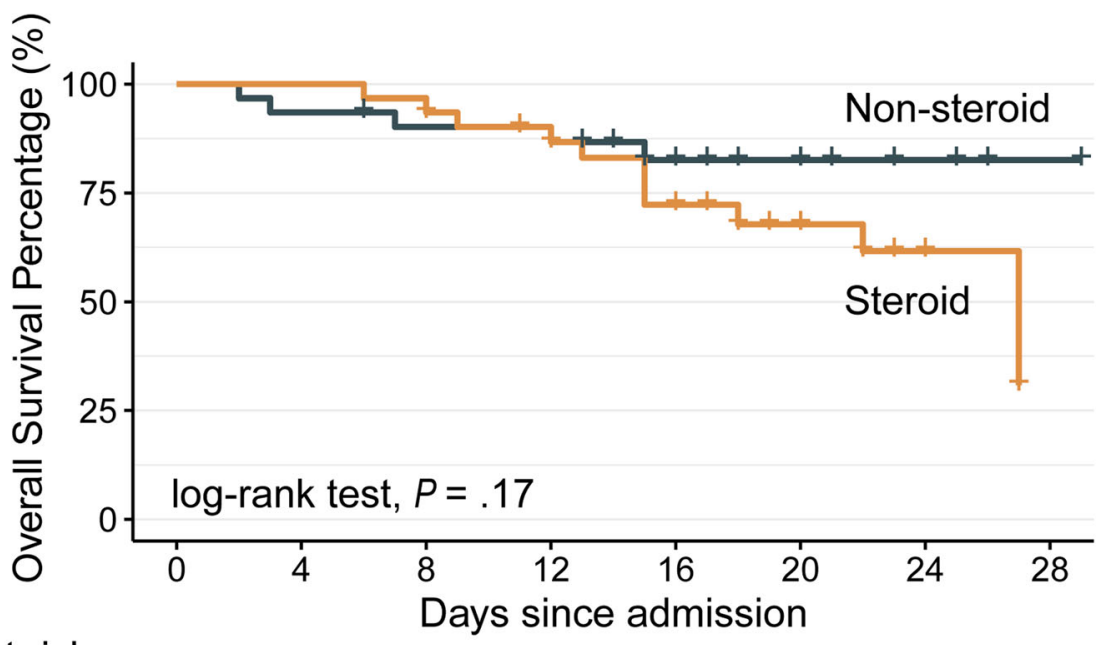

No. at risk

\begin{tabular}{l|cccccccc} 
Non-steroid & 31 & 29 & 27 & 26 & 19 & 11 & 4 & 2 \\
Steroid & 31 & 31 & 30 & 26 & 20 & 12 & 8 & 0 \\
\cline { 2 - 8 } & 0 & 4 & 8 & 12 & 16 & 20 & 24 & 28
\end{tabular}

Fig. 1 Survival curves stratified by adjuvant corticosteroid treatment. Thirty-one critically ill patients with COVID-19 who received corticosteroid treatment (yellow line) are compared with 31 matched control subjects (green line) who did not receive corticosteroid treatment

increased corticosteroid dosage was significantly associated with elevated mortality risk after adjustment for administration duration $(P=0.003)$; every $10-\mathrm{mg}$ increase in dosage was associated with additional $4 \%$ mortality risk (adjusted HR 1.04, 95\% CI 1.01-1.07).

We acknowledged limitations. First, we did not distinguish patients who received corticosteroids for underlying disease (e.g., COPD), the number of which was however small. Second, PSM is limited by adjusting for observed covariables only; randomized placebo-controlled trials are therefore warranted. Altogether, our investigation indicated limited effect of corticosteroid therapy could pose to overall survival of critically ill patients with COVID-19. Given the adverse effects, corticosteroid therapy must be commenced with caution, and prudent dosage should be promoted under certain circumstances.

\section{Acknowledgements}

We would like to thank all the hospital staff members for their efforts in collecting the information used in this study and all the patients who consented to donate their data for the analysis and the medical staff members who are on the front line of caring for patients.

\section{Authors' contributions}

Conceptualization: X. Lu, T. Chen. Acquisition, analysis, or interpretation of the data: J. Wang, Y. Wang, X. Lu, T. Chen. Statistical analysis: X. Lu, F. Yan. Investigation: X. Lu, T. Chen, Y. Wang. Drafting of the manuscript and editing: X. Lu, T. Chen, Y. Wang. Funding acquisition: J. Wang, Y. Wang, F. Yan. Supervision: J. Wang, F. Yan. The author(s) read and approved the final manuscript.
Funding

This work was supported by the National Key R\&D Program of China (2019YFC1711000), the National Natural Science Foundation of China (81973145), the "Double First-Class" University Project (CPU2018GY09), the China Postdoctoral Science Foundation (2019 M651805), the Science Foundation of Jiangsu Commission of Health (H2018117), and the Emergency Project for the Prevention and Control of the Novel Coronavirus Outbreak in Suzhou (SYS2020012).

\section{Availability of data and materials}

Dr. J. Wang had full access to all of the data in the study. After publication, the data will be made available to others on reasonable requests after approval from the corresponding author (J.W, dr_wangjun@suda.edu.cn) and Wuhan Tongji Hospital.

Ethics approval and consent to participate

Ethical approval was waived by the Ethics Committee of Tongji Hospital

(Wuhan, China) in view of the retrospective and observational nature of the

study and all the procedures being performed were part of the routine care.

\section{Consent for publication}

The informed consents of patients were waived by the Ethics Commission of Tongji Hospital (Wuhan, China) for the rapid emergence of this epidemic.

\section{Competing interests}

The authors declared no conflict of interest.

\section{Author details}

${ }^{1}$ State Key Laboratory of Natural Medicines, Research Center of Biostatistics and Computational Pharmacy, China Pharmaceutical University, Nanjing 210009, China. ${ }^{2}$ Medical School of Nanjing University, Nanjing, China. ${ }^{3}$ Department of Radiology, The Affiliated Nanjing Drum Tower Hospital of Nanjing University Medical School, Nanjing, China. ${ }^{4}$ Department of Intensive Care Medicine, The First Affiliated Hospital of Soochow University, Suzhou, China. 
Received: 4 May 2020 Accepted: 11 May 2020

Published online: 19 May 2020

\section{References}

1. Zhou F, Yu T, Du R, Fan G, Liu Y, Liu Z, Xiang J, Wang Y, Song B, Gu X. Clinical course and risk factors for mortality of adult inpatients with COVID19 in Wuhan, China: a retrospective cohort study. Lancet. 2020;6736(20): 30566-73.

2. Organization WH: Clinical management of severe acute respiratory infection (SARI) when COVID-19 disease is suspected: interim guidance, 13 March 2020. In: World Health Organization; 2020.

3. Arabi YM, Mandourah Y, Al-Hameed F, Sindi AA, Almekhlafi GA, Hussein MA, Jose J, Pinto R, Al-Omari A, Kharaba A. Corticosteroid therapy for critically ill patients with Middle East respiratory syndrome. Am J Respir Crit Care Med. 2018;197(6):757-67.

4. Rosenbaum PR, Rubin DB. The central role of the propensity score in observational studies for causal effects. Biometrika. 1983;70(1):41-55.

5. Kim S-H, Hong S-B, Yun S-C, Choi W-I, Ahn J-J, Lee YJ, Lee H-B, Lim C-M, Koh Y. Corticosteroid treatment in critically ill patients with pandemic influenza A/H1N1 2009 infection: analytic strategy using propensity scores. Am J Respir Crit Care Med. 2011;183(9):1207-14.

\section{Publisher's Note}

Springer Nature remains neutral with regard to jurisdictional claims in published maps and institutional affiliations.

Ready to submit your research? Choose BMC and benefit from:

- fast, convenient online submission

- thorough peer review by experienced researchers in your field

- rapid publication on acceptance

- support for research data, including large and complex data types

- gold Open Access which fosters wider collaboration and increased citations

- maximum visibility for your research: over $100 \mathrm{M}$ website views per year

At BMC, research is always in progress.

Learn more biomedcentral.com/submissions 